\title{
CANTIERE DEL SILENZIO
}

\author{
di Gianni D’Elia
}

Son ferme da quanti anni, le tre grandi gru, che sulle lunghe zampe cigolanti dirigevano l'orchestra del cantiere, lo stridio delle frese, i colpi dei magli,

il sibilo stellante delle fiamme ossidriche, zittite dalle rauche sirene, quando anche il mare applaude alla pausa del pasto e delle schiene?...

Da quel silenzio spuntan le lamiere, drizzate oltre il muro, prue e chiglie troncate a netto, sullo squero a secco, lasciate senza poppe a farsi nere...

Di là dal fiume, pedalando in Baia, si pensa a come fare vere navi sia ormai cassato dal bel Circo Italia, guardando entrarci in volo i soli gabbiani...

Lì, come gli scheletri dei ponteggi, così il poeta, e così il suo rimare, tubi innocenti, maneggi e dileggi, se mai nessuno li rimette in mare...

Pesaro, ottobre 2011 